\title{
PENGEMBANGAN ALAT BANTU HITUNG BERBASIS MATLAB PADA MATERI APLIKASI HUKUM BERNOULLI
}

\author{
Bergita Gela M Saka ${ }^{1}$, Fita Widiyatun ${ }^{2}$ \\ ${ }^{1}$ Pendidikan Fisika, Fakultas Keguruan dan Ilmu Pendidikan, Universitas Kristen Indonesia Toraja \\ Jalan Nusantara No.12 Makale, Kabuten Tana Toraja \\ ${ }^{2}$ Teknik Informatika, Fakultas Teknik dan Ilmu Komputer, Universitas Indraprasta PGRI \\ Jalan Nangka Raya No. 58 C, Jagakarsa, Jakarta Selatan \\ $\underline{{ }^{1} \text { bergitagelasukumusaka@gmail.com, }}, \underline{2 \text { fita.wdy@gmail.com }}$
}

\begin{abstract}
ABSTRAK
Matlab merupakan salah satu software yang dapat digunakan untuk membantu dalam menyelesaikan persoalan matematis. Penggunaan Matlab sebagai alat bantu hitung atau kalkulator hitung telah sering dilakukan diberbagai bidang keilmuan, terutaman dibidang fisika. Tujuan dari penelitian ini adalah membuat alat bantu hitung dengan menggunakan GUI Matlab untuk materi pada aplikasi Hukum Bernoulli. Metode yang digunakan adalah penelitian pengembangan dengan pendekatan 4D (define, design, develop and dessiminate), hanya saja penelitian ini baru sampai pada tahap pengembangan. Hasil dari penelitian adalah telah dibuat alat bantu hitung dengan menggunakan GUI Matlab untuk materi pada aplikasi Hukum Bernoulli, diantaranya gaya angkat pada pesawat terbang dan Asas Toricelli.
\end{abstract}

Kata Kunci: GUI Matlab, alat bantu hitung, Hukum Bernoulli, Gaya angkat pesawat, Asas Toricelli

\begin{abstract}
Matlab is a software that can be used to help solve mathematical problems. The use of Matlab as a tool for calculating or calculating calculators has often been carried out in various scientific fields, especially in the field of physics. The purpose of this study is to make a calculation tool using the Matlab GUI for material on the application of Bernoulli's Law. The method used is development research with a 4 D approach (define, design, develop and dessiminate), it's just that this research has only reached the development stage. The result of this research is that a calculation tool has been made using the Matlab GUI for the application material of Bernoulli's Law, including the lifting force on an airplane and the Toricelli principle.
\end{abstract}

Key Word: Matlab GUI, calculator, Bernoulli's law, Aircraft lift, Toricelli's principle

\section{PENDAHULUAN}

Matlab atau Matrix Laboratory dapat digunakan sebagai media untuk membantu dalam melakukan perhitungan matematis. Telah banyak penelitian tentang penggunaan software ini guna pembuatan media alat bantu hitung atau kalkulator. Diantaranya pada bidang Fisika, pernah digunakan untuk membuat kalkulator pada materi kinematika atau pergerakan benda tanpa memperhatikan gaya yang bekerja pada benda tersebut. (Alhidayatuddiniyah \& Siwi Puji Astuti, 2020; Handayani \& Huda, 2021; Yosua et al., 2019). Hukum Kepler (Sari et al., 2021). Selain itu juga pernah digunakan untuk membuat alat bantu hitung untuk materi usaha dan energi (Sumarni et al., 2021). Pernah juga digunakan untuk materi pada dinamika gerak system katrol (Nugraha, 2020). Serta, pernah juga digunakan untuk materi suhu dan kalor (Zulmi et al., 2018).
Hukum Bernaulli merupakan hukum dalam penyelesaian pada materi fluida bergerak. Hukum ini dapat digunakan pada beberapa aplikasi atau kasus-kasus, diantaranya pada Asas Toricelli, venturimeter, tabung pitot, gaya angkat pada pesawat terbang, dan yang lainnya (Abdullah, 2016). Penerapan Hukum Bernoulli untuk mengatasi krisis air pernah dilakukan di Kabupaten Solok (Marzuki et al., 2021). Penerapan yang dilakukan adalah pada sistem perpipaan untuk memenuhi kebutuhan warga masyarakat setempat, diantaranya mandi, mencuci, serta mengairi sawah.

Tujuan dari penelitian ini adalah membuat alat bantu hitung pada materi fluida tentang Hukum Bernoulli. Penerapan alat bantu hitung ini difokuskan pada Asas Toricelli dan gaya angkat Bernoulli pada sayap pesawat terbang. Manfaat dari penelitian ini adalah dengan adanya alat bantu hitung dapat 
mempermudah dalam perhitungan dan penyelesaian kasus-kasus fisika, materi fluida tentang aplikasi Hukum Bernoulli yaitu Asas Toricelli dan gaya angkat Bernoulli pada sayap pesawat terbang.

\section{METODE PENELITIAN}

Metode yang digunakan pada penelitian ini adalah penelitian pengembangan dengan pendekatan 4D (define, design, develop, dan dessiminate). Akan tetapi, tahapan yang telah dilakukan baru mencapai pada perancangan dan pengembangan produk, belum sampai pada tahapan pengujian terhadap respon pengguna.

Produk yang dikembangkan adalah alat bantu hitung pada materi fluida khususnya aplikasi dari Hukum Bernaulli. Adapun tahapan atau langkah-langkah yang telah dilakukan seperti ditunjukkan pada gambar di bawah ini (Gambar 1).

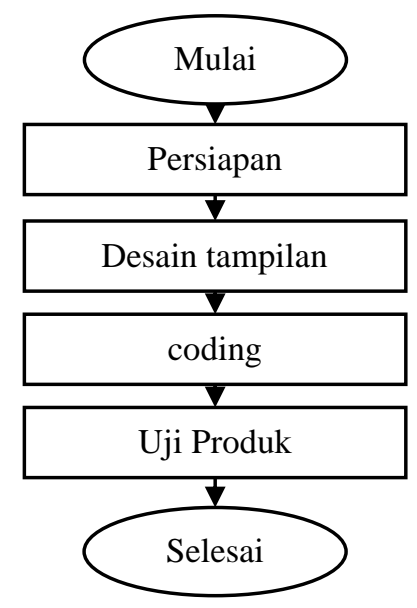

Gambar 1. Tahapan pembuatan produk

Tahapan persiapan berisikan studi literatur yang berkaitan dengan penelitian, serta persiapan alat pendukung lainnya seperti laptop dan software matlab yang akan digunakan. Laptop yang digunakan adalah Asus VivoBook dengan AMD Ryzen 5 Ram 8 GB, sedangkan Software matlab yang digunakan untuk membuat produk yaitu Matlab 2014a.

Tahapan selanjutnya adalah desain tampilan dari alat bantu hitung yang akan dibuat di dalam GUI Matlab. Setelah mendesain, kemudian melakukan pengkodingan (penulisan listing program) yaitu mengatur background tampilan, menuliskan variabel dan perintah terhadap alat bantu hitung. Tahapan terakhir adalah pengujian produk. Pengujian dilakukan dengan mencocokan hasil dari perhitungan di alat bantu dengan perhitungan secara manual.

Perintah perhitungan yang dimasukkan ke dalam listing program adalah persamaanpersamaan untuk menghitung gaya angkat Bernoulli pada sayap pesawat terbang dan Asas Toricelli. Berdasarkan persamaan Hukum Bernoulli (Abdullah, 2016):

$P_{1}+\frac{1}{2} \rho v_{1}^{2}+\rho g h_{1}=P_{2}+\frac{1}{2} \rho v_{2}^{2}+\rho g h_{2}$

Dengan menggunakan persamaan Hukum Bernoulli di atas, kita bisa mencari besar gaya angkat Bernoulli pada sayap pesawat terbang dengan persamaan :

$$
\Delta F=\frac{1}{2} \rho\left(v_{2}^{2}-v_{1}^{2}\right) A
$$

Selain persamaan gaya angkat pesawat di atas, persamaan (1) juga dapat diturunkan sehingga memperoleh persamaan untuk menghitung laju aliran air yang melewati keran :

$$
v_{\text {keran }}=\sqrt{2 g\left(h_{\text {air penampungan }}-h_{\text {keran }}\right)}
$$

Dengan diketahui $v_{\text {keran }}$, kita bisa menghitung besar debit air yang keluar melalui keran dengan persamaan :

debit air, $Q=A_{\text {keran }} \cdot v_{\text {keran }}$

Volume air yang mengalir dari keran :

$V=Q . t$

Laju penurunan air di bak penampungan :

$v_{\text {air penampungan }}=\frac{A_{\text {keran }}}{A_{\text {penampungan }}} v_{\text {keran }}$

Penurunan permukaan air di bak penampungan setelah $\mathrm{t}$ detik adalah :

$$
\Delta h=v_{1} \cdot t
$$

\section{HASIL DAN PEMBAHASAN}

Hasil yang diperoleh dari penelitian ini berupa suatu produk alat bantu hitung. Tampilan awal saat menjalankan produk tersebut ditunjukkan seperti pada Gambar 2. Disamping tulisan Hukum Bernoulli terdapat tombol dengan tulisan 'Gaya Angkat Bernoulli pada Pesawat Terbang' dan 'Asas Toricelli'. Saat salah satu tombol tersebut di 
klik maka akan diarahkan ke halaman alat hitungnya. Sebagai contoh, apabila mengeklik tombol 'Gaya Angkat Bernoulli pada Pesawat Terbang' maka akan diarahkan ke halaman pada Gambar 3. Tetapi apabila mengeklik tombol pada 'Asas Toricelli' maka akan diarahkan ke Gambar 5.

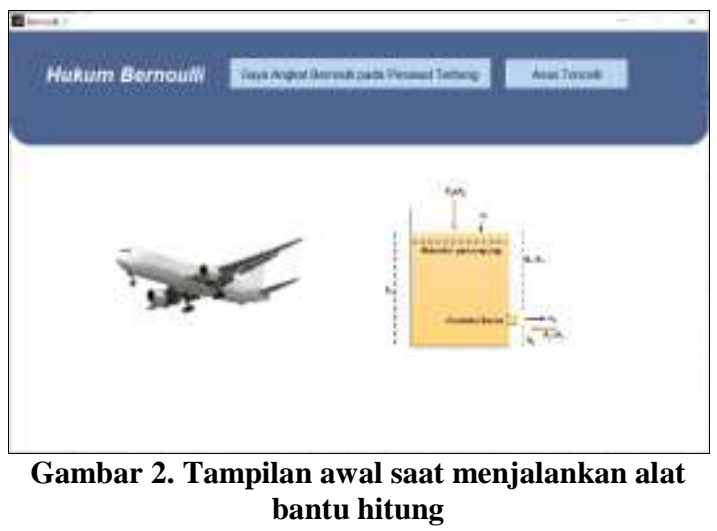

Tampilan pada halaman gaya angkat Bernoulli pada pesawat terbang, seperti pada Gambar 3 di bawah ini, variabel masukkan untuk melakukan perhitungan diantaranya : laju udara di sisi atas pesawat $(\mathrm{m} / \mathrm{s})$, laju udara di sisi bawah pesawat $(\mathrm{m} / \mathrm{s})$, luas total penampang sayap $\left(\mathrm{m}^{2}\right)$, dan massa jenis udara $\left(\mathrm{kg} / \mathrm{m}^{3}\right)$. Variabel yang dicari atau ditanyakan yaitu gaya angkat Bernoulli pada pesawat terbang $(\mathrm{N})$.

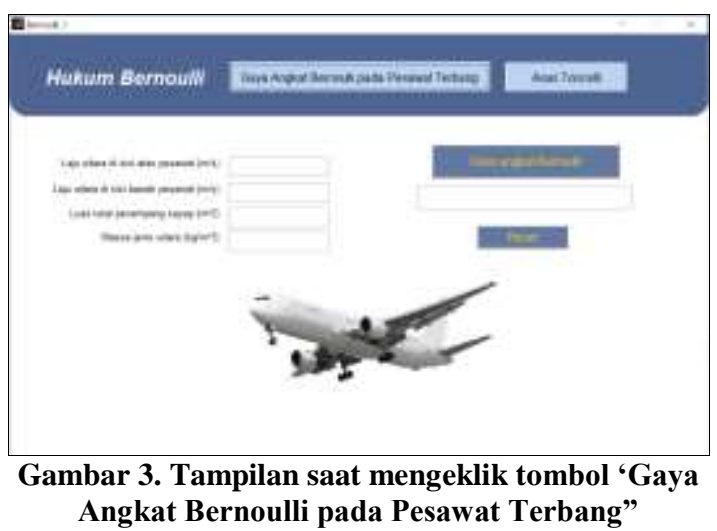

Apabila diketahui suatu pesawat terbang saat lepas landas memiliki laju udara di sisi atas sayap pesawat adalah $98 \mathrm{~m} / \mathrm{s}$, laju udara di sisi bawah sayap pesawat adalah $80 \mathrm{~m} / \mathrm{s}$, luas penampang total sayap pesawat adalah 440 $\mathrm{m} 2$, dan massa jenis udara adalah $1 \mathrm{~kg} / \mathrm{m} 3$. Hasil perhitungan dengan menggunakan alat bantu hitung yang dibuat, seperti ditunjukkan pada Gambar 4, yaitu diperoleh nilai sebesar 704.880 N. Nilai ini diperoleh setelah mengeklik tombol 'Gaya angkat Bernoulli' setelah memasukkan nilai-nilai pada variabel masukkannya. Tombol 'Reset' digunakan untuk mengatur ulang isian pada variabel masukan dan hasil menjadi kosong Kembali.

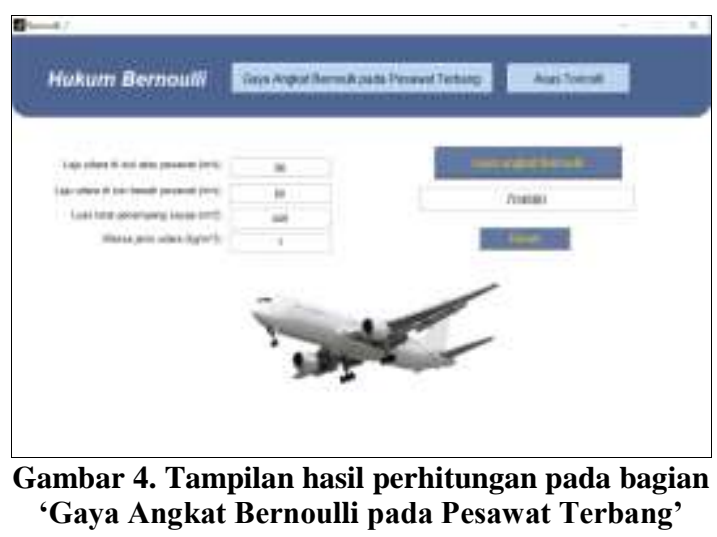

Perhitungan secara manual, sesuai dengan persamaan (2), diperoleh nilai gaya angkat Bernoulli pada sayap pesawat terbang yaitu :

$$
\begin{aligned}
\Delta F & =\frac{1}{2} \rho\left(v_{2}^{2}-v_{1}^{2}\right) A \\
& =\frac{1}{2} \cdot 1\left(98^{2}-80^{2}\right) 440 \\
& =704880 \mathrm{~N}
\end{aligned}
$$

Nilai dari perhitungan dengan alat bantu hitung dan perhitungan secara manual, diperoleh nilai yang sama. Perintah yang dituliskan di dalam script untuk menghitung besaran di atas adalah :

v2=str2double(get(handles.edit1,'string')); v1=str2double(get(handles.edit2,'string')); A1=str2double(get(handles.edit3,'string')); rho=str2double(get(handles.edit15, 'string'));

$\mathrm{F} 1=1 / 2^{*}{ }^{*} \mathrm{ho}^{*}\left(\left(\mathrm{v} 2^{\wedge} 2\right)-\left(\mathrm{v} 1^{\wedge} 2\right)\right)^{*} \mathrm{~A} 1$

set(handles.edit4,'string',F1);

Tampilan pada halaman Asas Toricelli, seperti ditunjukkan pada Gambar 5, mempunyai variabel-variabel masukkan diantaranya: ketinggian air pada penampung $/ \mathrm{h}_{1}(\mathrm{~m})$, ketinggian keran $/ \mathrm{h}_{2}(\mathrm{~m})$, diameter penampung $(\mathrm{m})$, diameter keran (m), dan waktu lamanya keran tersebut terbuka (detik). Variabel-variabel luaran yang dihitung dalam alat bantu hitung ini antara lain : laju aliran air yang mengalir melalui keran $(\mathrm{m} / \mathrm{s})$, debit air yang mengalir melalui keran $\left(\mathrm{m}^{3} / \mathrm{s}\right)$, volume air yang mengalir di dalam keran $\left(\mathrm{m}^{3}\right)$, laju penurunan air di bak penampungan $(\mathrm{m} / \mathrm{s})$, dan laju 
penurunan air di bak penampungan setelah $\mathrm{t}$ $\operatorname{detik}(\mathrm{m})$.

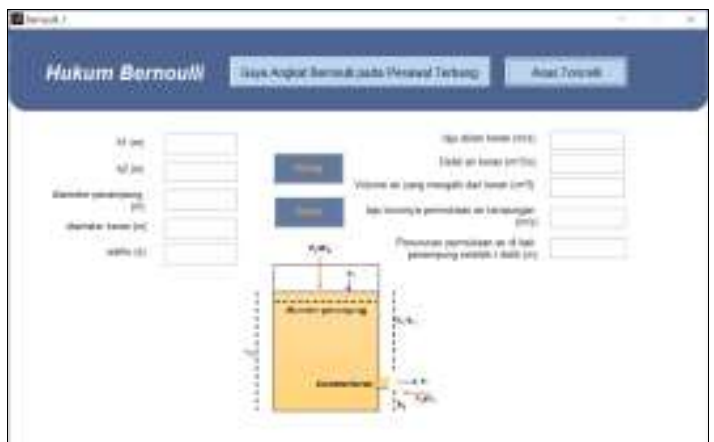

Gambar 5. Tampilan saat mengeklik tombol 'Asas Toricelli"

Apabila diketahui ketinggian air di dalam penampung terhadap tanah $\left(\mathrm{h}_{1}\right)$ adalah 125 $\mathrm{cm}$ atau $1,25 \mathrm{~m}$. ketinggian keran terhadap tanah $\left(\mathrm{h}_{2}\right)$ adalah $5 \mathrm{~cm}$ atau $0,05 \mathrm{~m}$. diameter penampungan air adalah $50 \mathrm{~cm}$ atau $0,5 \mathrm{~m}$. diameter keran adalah $1 \mathrm{~cm}$ atau $0,01 \mathrm{~m}$, dan saat keran dibuka, air mengalir selama 10 detik sampai keran kembali ditutup.

Berdasarkan perhitungan dengan menggunakan alat bantu hitung, Gambar 6, setelah memasukkan nilai-nilai pada variabel masukkan dan mengeklik tombol 'Hitung' diperoleh hasil laju aliran keran 4,89898 m/s, debit air keran $0,000384765 \mathrm{~m}^{3} / \mathrm{s}$, volume air yang mengalir dari keran $0,00384765\left(\mathrm{~m}^{3}\right)$, laju turunnya permukaan air tampungan $0,00195959 \mathrm{~m} / \mathrm{s}$, penurunan permukaan air di bak penampungan setelah 10 detik adalah 0,0195959 m.

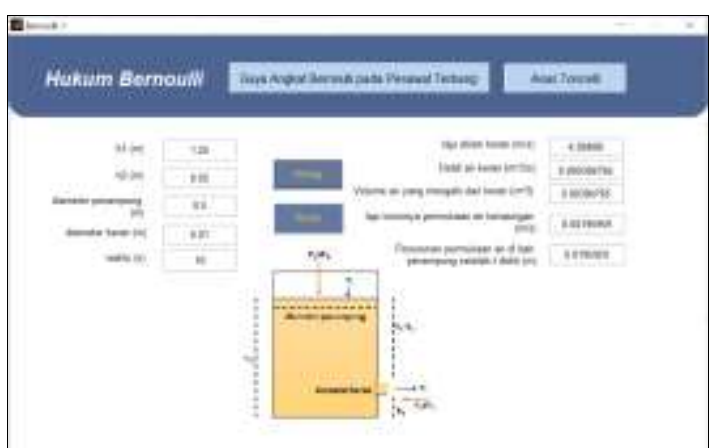

Gambar 6. Tampilan hasil perhitungan pada bagian 'Asas Toricelli'

Perhitungan secara manual dari beberapa variabel yang sudah diketahui, diperoleh laju aliran air yang mengalir keluar melewati keran adalah :

$v_{\text {keran }}=\sqrt{2 \cdot g \cdot\left(h_{\text {air penampungan }}-h_{\text {keran }}\right)}$

$$
\begin{aligned}
& =\sqrt{2 \cdot 10 \cdot(1,25-0,05)} \\
& =4,89898 \mathrm{~m} / \mathrm{s}
\end{aligned}
$$

Besar debit air yang keluar melalui keran :

$$
\begin{aligned}
& \text { jari }- \text { jari keran }\left(r_{\text {keran }}\right) \\
& \begin{array}{r}
\text { diameter keran } \\
=\frac{0,01}{2}=0,005 \mathrm{~m}
\end{array} \\
& \text { luas penampang keran }\left(A_{\text {keran }}\right) \\
& =\pi r_{\text {keran }}^{2} \\
& =3,14 \times 0,005^{2} \\
& =78,5 \times 10^{-6} \mathrm{~m}^{2} \\
& \text { debit air, } Q=A_{\text {keran }} . v_{\text {keran }} \\
& =78,5 \times 10^{-6} \times 4,89898 \\
& =384,56989 \times 10^{-6} \mathrm{~m}^{3} / \mathrm{s}
\end{aligned}
$$

Volume air yang mengalir dari keran :

$$
\begin{aligned}
V & =Q \cdot t \\
& =384,56989 \times 10^{-6} \times 10 \\
& =384,56989 \times 10^{-5} \mathrm{~m}^{3}
\end{aligned}
$$

Laju penurunan air di bak penampungan sebesar :

$$
\begin{aligned}
& r_{\text {penampungan }}=\frac{\text { diameter penampungan }}{2} \\
& \begin{aligned}
0,5 \\
2
\end{aligned}=0,25 \mathrm{~m} \\
& \begin{aligned}
A_{\text {penampungan }}= & \pi r^{2} \\
=3,14 x\left(0,25^{2}\right) & \\
= & 1962,5 \times 10^{-4} \mathrm{~m}^{2} \\
v_{\text {air penampungan }} & =\frac{A_{\text {keran }}}{A_{\text {penampungan }}} v_{\text {keran }} \\
& =\frac{78,5 \times 10^{-6}}{1962,5 \times 10^{-4}} \times 4,89898 \\
& =19,59592 \times 10^{-4} \mathrm{~m} / \mathrm{s}
\end{aligned}
\end{aligned}
$$

Penurunan permukaan air di bak penampungan setelah 10 detik adalah :

$$
\begin{aligned}
\Delta h & =v_{1}, t \\
& =19,59592 \times 10^{-4} \times 10 \\
& =19,59592 \times 10^{-3} \mathrm{~m}
\end{aligned}
$$

Hasil-hasil perhitungan secara manual di atas sama dengan hasil yang diperoleh dengan bantuan alat hitung pada Gambar 6. Perintah yang dituliskan di dalam script untuk menghitung besaran-besaran di atas adalah : h11=str2double(get(handles.hh, 'string')); h22=str2double(get(handles.edit13, 'string')); d11=str2double(get(handles.edit14,'string')); d22=str2double(get(handles.dd, 'string')); t11=str2double(get(handles.tt,'string')); 
v2=sqrt $(2 * 10 *(h 11-h 22))$;

$r 1=0.5 * d 22$

$\mathrm{Ab}=\mathrm{pi}^{*}\left(\mathrm{r} \mathbf{1}^{\wedge} 2\right)$;

$\mathrm{Q}=\mathrm{Ab} * \mathrm{v} 2$;

deltaV=Q*t11;

$\mathrm{r} 2=0.5 * \mathrm{~d} 11$

$\mathrm{Aa}=\mathrm{pi}^{*}\left(\mathrm{r} 2^{\wedge} 2\right)$;

$\mathrm{v} 1=(\mathrm{Ab} / \mathrm{Aa})^{*} \mathrm{v} 2$;

delta_h=v1*t11;

set(handles.edit8,'string',v2);

set(handles.edit9, 'string',Q);

set(handles.edit10,'string', deltaV);

set(handles.edit11,'string',v1);

set(handles.edit12,'string',delta_h);

Berdasarkan hasil, perhitungan, dan analisis di atas, maka alat bantu hitung untuk materi fluida pada aplikasi Hukum Bernoulli, gaya angkat Bernoulli pada pesawat terbang dan Asas Toricelli, bahwa alat bantu hitung tersebut dapat digunakan dengan baik. Hal ini terlihat saat memproses run untuk menjalankan alat bantu hitung tersebut tidak ada pernyataan error pada command windows Matlab. Selain itu, hasil perhitungan matematis secara manual dan menggunakan alat bantu hitung mempunyai nilai yang sama, hanya berbeda pada penempatan tanda komanya.

Pada bidang Pendidikan, penggunaan alat peraga Aeromodelling dapat meningkatkan pemahaman siswa tentang Hukum Bernoulli (Kholida et al., 2021). Media pembelajaran untuk meningkatkan pemahaman materi fisika tidak hanya terbatas pada alat peraga, GUI Matlab juga dapat digunakan sebagai media pembelajaran bidang materi fisika (Widiyatun et al., 2021). Alat bantu hitung yang telah dibuat dengan menggunakan GUI Matlab dapat digunakan sebagai media pembelajaran untuk materi fluida, khususnya aplikasi pada Hukum Bernoulli.

\section{SIMPULAN DAN SARAN}

Telah dibuat alat bantu hitung untuk membantu dalam perhitungan materi fluida pada aplikasi Hukum Bernoulli menggunakan GUI Matlab. Aplikasi tersebut diantaranya gaya angkat Bernaoulli pada pesawat terbang dan Asas Toricelli.

Perlu adanya penelitian lebih lanjut tentang peningkatan pemahaman peserta didik dengan menggunakan alat bantu hitung tersebut. Sehingga alat bantu hitung tersebut diketahui tidak hanya dapat digunakan untuk membantu dalam proses perhitungan /penyelesaian soal.

\section{DAFTAR PUSTAKA}

Abdullah, M. (2016). Fisika Dasar I. Institut Teknologi Bandung.

Alhidayatuddiniyah, T. W., \& Siwi Puji Astuti. (2020). Perancangan Aplikasi Kalkulator Kinematika pada Mata Kuliah Fisika Gerak Berbasis Matlab. Prosiding Seminar Nasional Sains (Sinasis), 1(1), 24-28.

Handayani, S., \& Huda, D. N. (2021). Kalkulator Gerak Lurus Berubah Beraturan dan Gerak Lurus Berubah Beraturan Berbasis Matlab. 3(1), 2226.

Kholida, S. I., Suprianto, \& Titin Sunarti. (2021). Growing Science Process Skills and Student's Understanding of Physics Concepts on Bernoulli's Law Using Aeromodelling Props. Kasuari: Physics Education Journal (KPEJ) Universitas Рариа, 4(1), 21-31.

Marzuki, Pohan, A. F., Afdal, \& Sutantyo, T. E. P. (2021). Penerapan Konsep Hukum Bernoulli untuk Mengatasi Krisis Air pada Kelompok Tani Padi di Kenagarian Katialo Kabupaten Solok. 4(1), 54-60.

Nugraha, A. M. (2020). Graphic User Interface (GUI) untuk materi dinamika gerak sistem katrol berbasis matlab. Navigation Physics: Journal of Physics Education, 1(2), 51-58. https://doi.org/10.30998/npjpe.v1i2.200

Sari, L., Guspita, N., Srigutomo, W., Amalia, I. F., \& Adimayuda, R. (2021). Application of GUI Matlab in physics: Planetary motion (Kepler's Law). Journal of Physics: Conference Series, 1987(1). https://doi.org/10.1088/17426596/1987/1/012045

Sumarni, R. A., Juliardi, M., Widiyatun, F., Astuti, I. A. D., Okyranida, I. Y., \& Bhakti, Y. B. (2021). MATLAB-based physics calculator: Alternative for 
learning media for work and energy concept. Journal of Physics: Conference Series, 1806(1). https://doi.org/10.1088/17426596/1806/1/012022

Widiyatun, F., Sumarni, R. A., \& Yona, I. (2021). GUI Matlab untuk Pembuatan Kalkulator Fisika Gerak Media Belajar Mahasiswa Teknik Informatika. Prosiding Seminar Nasional Sains (SINASIS 2), 2(1), 435-442.

Yosua, R., Fauzan, A., Kistiani, K., \& Astuti, I. A. D. (2019). Aplikasi KALFIS (Kalkulator Fisika) Berbasis Matlab untuk Membantu Analisis Eksperimen Fisika. Navigation Physics: Journal of Physics Education, 1(2), 59-62. https://doi.org/10.30998/npjpe.v1i2.201

Zulmi, N., Darmayanti, N. W. S., \& Zulkarnain, Z. (2018). Pengembangan Rumfis (Rumus Fisika) Berbasis Program Matlab Pada Materi Suhu Dan Kalor Untuk Meningkatkan Motivasi Belajar Siswa SMPN 2 Labuapi Kelas VII Tahun Ajaran 2017/2018. ORBITA: Jurnal Kajian, Inovasi Dan Aplikasi Pendidikan Fisika, 4(1), 8. https://doi.org/10.31764/orbita.v4i1.469 